\title{
Effect of coolant flow rate on surface topography when precision grinding silicon using mounted diamond pins
}

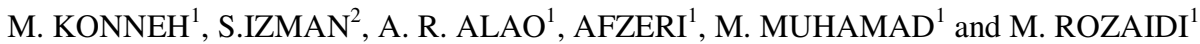 \\ ${ }^{1}$ International Islamic University Malaysia, Department of Manufacturing and Materials Engineering, \\ Faculty of Engineering, P. O. Box 10, 50728 Kuala Lumpur, Malaysia \\ ${ }^{2}$ Univeristi Teknologi Malaysia, Faculty of Mechanical Engineering, Department of Production and \\ Industrial Engineering, 81310 UTM, Skudai, Johor, Malaysia
}

\begin{abstract}
Much effort has been made in machining hard and brittle materials. However, less attention is paid to the amount of coolant that contributes to generating ductile streaks especially when machining small areas on brittle materials like silicon. This paper presents partial-ductile grinding of mono-crystalline silicon using $64 \mu \mathrm{m}$ resinoid-bonded diamond mounted pins on conventional MAHO NC vertical Milling machine. Ground work-pieces were examined both qualitatively and qualitatively. Evaluations of the results reveal condition of optimum flow rate where minimal micro fractures occurred and indicating surface finish as low as $30 \mathrm{~nm}$. Interrelationship between machining parameters is also established
\end{abstract}

Keywords: Partial-ductile grinding, flow rate, Silicon, diamond grinding pins, surface topography, micro fracture

\section{Introduction}

Brittle materials are difficult to machine accurately. Conventionally the problem in grinding hard and brittle materials is surface fractures and cracks at the machined workpiece surface. Ductile-mode machining has often been a desirable technique for precisely removing unwanted material from hard and brittle semiconductor materials at micro and/or nano scale. This minimizes or if possible avoids micro-cracks or fractures at the machined work-piece surfaces. This technique is essential for manufacturing most high-tech functional parts and it is more effective than conventional finishing process. It is proven that ductile mode grinding of glass can reduce the polishing time remarkably to meet today's requirement for higher productivity and quality $[[1,2,3]$.

In machining process, cutting fluid is important. The advantages of using fluid in grinding have been recognized by many researchers $[4,5]$. Cutting fluid is used extensively in machining for some reason such as, to reduce friction and wear of the cutting tool so improving tool life and give better surface finish. It can also reduce force and energy consumption, cool the cutting zone, thus reduce workpiece temperature and distortion, it also washes away chip on the work material and lastly protects the newly machine surface from environmental corrosion. Adequate flow rate through the grinding contact is needed in order to achieve high precision of surface finishing. There is therefore a need for accurate prediction of the parameters that influence the flow rate through the grinding zone. This flow rate is termed useful flow rate since a large proportion of the flow rate may bypass the grinding contact and is therefore regarded as non-useful [6]. Fluid flow under a grinding wheel has come under investigation due to an attempt to determine the 'useful flow rate [7]. The useful flow rate is the quantity of cutting fluid which passes through the grinding zone and affects the grinding mechanism. A theoretical study by Guo and Malkin [5] based on experimental results by Engineer et al. [4], concluded that the useful flow rate is equal to the amount of fluid retained in the grinding wheel pores from the point of application to the point where grinding commences.

However, not much is done on the amount of coolant that contributes to generating good surface quality in terms of ductile streaks, especially when machining small areas on brittle materials like silicon. It has been observed, in the earlier work of author [8], that the flow of coolant into the vicinity of machining affected the amount of ductile streaks produced on the surface of ground mono crystalline silicon.

This paper is focused on investigating the effect of coolant on surface topography when precision grinding silicon using $64 \mu \mathrm{m}$ resinoid-bonded diamond mounted pins.

The process parameters considered in this work are infeed (depth of cut), feed rate and flow rate. The low rotational speed (maximum $6300 \mathrm{rev} / \mathrm{min}$ ) of a conventional 5-axis NC Deckel MAHO Milling machine was enhanced to 70,000 rev/min when an ultra-precision high speed attachment (PLANET 850) was fixed to the main spindle of the machine to facilitate grinding of the work-piece material at low forces. Statistical approach was employed for experimental design and analysis of numerical data obtained from the experiments. Qualitative examination of the ground work-pieces was done using optical and scanning electron microscopy techniques and quantitative assessment done on a Mitutoyo surface measuring machine. Evaluations of the results reveal condition of optimum flow rate where minimal micro fractures occurred and surface finish as low as $30 \mathrm{~nm}$ obtained. Analysis also established interrelationship between machining parameters. 


\section{Work-piece and tool materials}

\subsection{The work-piece material}

The workpieces used in this research work are thin silicon blocks each of dimensions $15 \mathrm{~mm}$ x $15 \mathrm{~mm}$ × 6 $\mathrm{mm}$, glued into aluminium blocks shown in Fig.1.

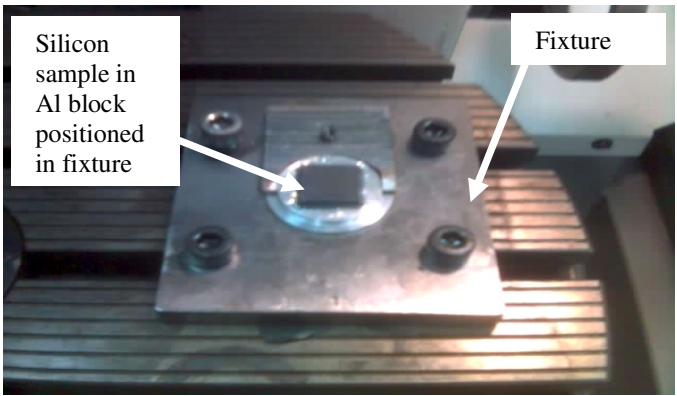

Figure 1: A silicon sample being rigidly held on a special fixture

\subsection{The tool material}

The tool material for the experimental work is resinbonded mounted grinding pins, usually used for jig grinding operations. This is depicted in Figure 2.

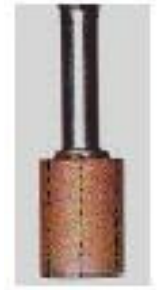

Figure 2: Details of a diamond grinding pin (1A1W-5-6-1.5*D64 K-888RY C100) used to carry out precision grinding of silicon.

\section{Equipment and Instruments}

The following equipment and instruments were used: Low Flow Liquid Flow Indicators: The coolant flow rate was measured using a low flow liquid flow indicator (Grillon TR55) manufactured by Parker Hannifin Filtration; 5-axis NC DMU 35M DECKEL MAHO: The 5-axis NC DMU 35M DECKEL MAHO vertical milling machine was used for experimentation; Surface Roughness Measurement Instrument: Surface Roughness Measurements were done on Mitutoyo Surftest (SV-514) which uses Surfpak $\{\mathrm{V} 4.10$ (2) $\}$ software; Optical Microscope: Optical microscope was used to examine the surface topography of grounded silicon. It has a magnification up to 500 times; Scanning Electron Microscope (SEM): SEM was used to assess selected surfaces of the results obtained from optical microscopy examinations.

\section{Experiment and Measurement Procedures}

The experimental set-up and the procedure for carrying out the experiments are discussed in this section. The design of experiment (DOE) is also highlighted.

\subsection{Parameters}

The independent factors considered are: speed (constant) $=70000 \mathrm{rpm}$ at pressure equivalent to $3 \mathrm{~kg} / \mathrm{cm}^{2}$; depth of cut $=5,10,20(\mu \mathrm{m})$; feed rate $=2.5,5,10$ $(\mathrm{mm} / \mathrm{min})$ and flow rate $=3,5,7 \mathrm{~L} / \mathrm{min}$.

\subsection{Design of experiments}

Experiments were designed using Design Expert 7.0.3 software by using Box-Behnken design of experiments

\subsection{Experiment Set-up and measurement Procedure}

The maximum spindle speed of the machine used for experimentation is $6300 \mathrm{rpm}$ Figure 3. Its spindle was modified by attaching to it with an ultra-precision high speed jig grinder (NSK Planet 850) to provide the required rotational speed $(70000 \mathrm{rpm})$ based on adjusted pressure of $0.3 \mathrm{MPa}$.

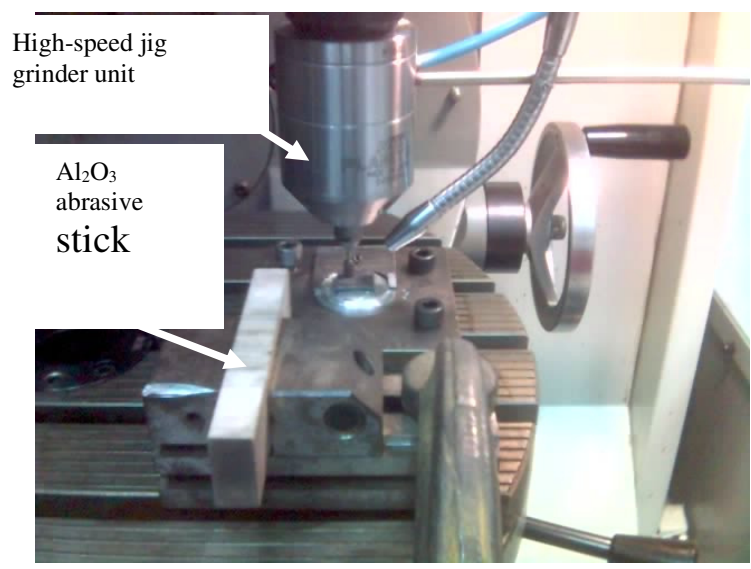

Figure 3: (a) The experimental set-up showing a highspeed jig grinder attached on DECKEL MAHO NC vertical milling main spindle

A work-piece was flattened before any experimental trial. That was to ensure that the surface of the silicon workpiece was of any damage that would affect the grinding process. The coolant is supplied by the machine when the machine is on; before the experimen $\iota$ can be run we need to check the coolant flow rate using the indicator. The flow rate was adjusted and recorded as desired for an experimental run. The coolant used was Castrol Miracol 80 with ratio of 1: 50 (Castrol Miracol to water). The experiments were carried out in accordance with the design of experiment. The dressing of the grinding pin was done before starting each new grinding condition. The dressing stick used was an $\mathrm{Al}_{2} \mathrm{O}_{3}$ abrasive. The Mitutoyo Surftest (SV-514) was used to measure roughness parameters of ground silicon surfaces. Hence the parameters $R_{a}$, and $R_{t}$ were recorded based on $0.25 \mathrm{~mm}$ sampling length. Optical microscope was used to examine all the ground surfaces of silicon. SEM was used to assess some selected surfaces that were perceived to contain ductile streaks from optical microscopic viewpoint. 


\section{Experimental Results and Discussion}

\subsection{Surface Roughness}

The results obtained from the experiments are summarized in Table 1

Table 1: Result of surface roughness of ground $\mathrm{Si}$ surfaces based on Design Expert 7.0.3 software.

\begin{tabular}{|c|c|c|c|c|c|c|}
\hline Run & Block & $\begin{array}{c}\text { Factor } 1 \\
\text { A: DOC } \\
(\mu \mathrm{m})\end{array}$ & $\begin{array}{c}\text { Factor } 2 \\
\text { B : Feed } \\
\text { rate } \\
\text { (mm/min) }\end{array}$ & $\begin{array}{c}\text { Factor } 3 \\
\text { C: Coolant } \\
\text { flow rate } \\
(\mathrm{L} / \mathrm{min})\end{array}$ & $\begin{array}{c}\text { Response } 1 \\
\operatorname{Ra}(\mu \mathrm{m})\end{array}$ & $\begin{array}{c}\text { Response 2 } \\
\operatorname{Rt}(\mu \mathrm{m})\end{array}$ \\
\hline 1 & Block 1 & 10 & 5 & 5 & 0.130 & 1.570 \\
\hline 2 & Block 1 & 5 & 10 & 5 & 0.116 & 1.510 \\
\hline 3 & Block 1 & 10 & 2.5 & 3 & 0.096 & 1.280 \\
\hline 4 & Block 1 & 20 & 2.5 & 5 & 0.080 & 1.070 \\
\hline 5 & Block 1 & 5 & 2.5 & 5 & 0.076 & 1.270 \\
\hline 6 & Block 1 & 10 & 10 & 7 & 0.030 & 0.410 \\
\hline 7 & Block 1 & 20 & 5 & 7 & 0.160 & 1.930 \\
\hline 8 & Block 1 & 5 & 5 & 7 & 0.120 & 1.470 \\
\hline 9 & Block 1 & 10 & 5 & 5 & 0.135 & 1.572 \\
\hline 10 & Block 1 & 10 & 5 & 5 & 0.130 & 1.570 \\
\hline 11 & Block 1 & 20 & 5 & 3 & 0.170 & 2.070 \\
\hline 12 & Block 1 & 10 & 2.5 & 7 & 0.090 & 1.030 \\
\hline 13 & Block 1 & 20 & 10 & 5 & 0.143 & 1.413 \\
\hline 14 & Block 1 & 5 & 5 & 3 & 0.163 & 1.950 \\
\hline 15 & Block 1 & 10 & 10 & 3 & 0.096 & 1.090 \\
\hline
\end{tabular}

\subsubsection{Statistical Analysis}

The results in Table 1 have been analyzed using the Design Expert 7.0.3 software. The lack fit summary suggests quadratic and 2-factor interaction.

Box-Cox plot suggests that there is no need for transforming Ra data since lambda is equal to 1 .

Based on $\mathrm{P}$ valve in the ANOVA table, the model equations for $\mathrm{Ra}$ were developed since $\mathrm{P}$ valve is equal to or less than 0.05 for the model and its terms.

Table 2: The ANOVA of the Model

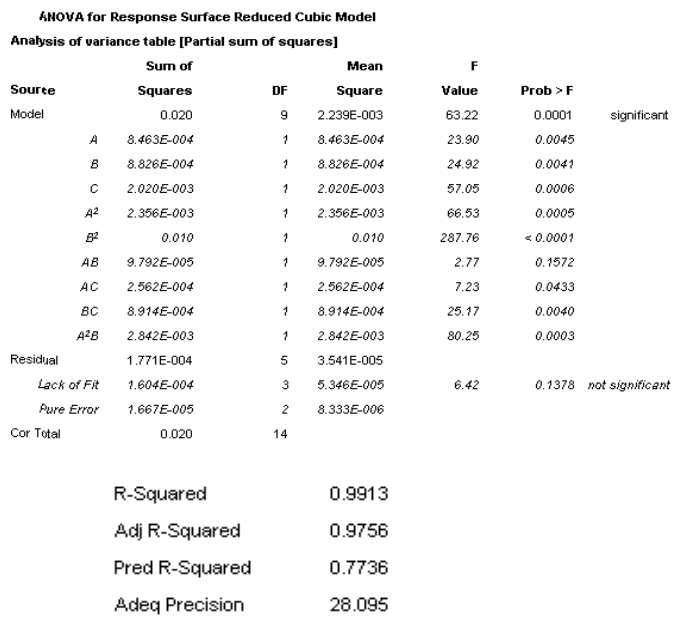

\section{Final Equation in Terms of Actual Factors:}

Ave. $R_{a}=-0.10701+0.016026$ Doc +0.088104 Feed rate $2.75000 \mathrm{E}-003$ Coolant flow rate $-7.31558 \mathrm{E}-004 \mathrm{Doc}^{2}$ 4.29756E-003Feed rate ${ }^{2}-4.86433$ E-003Doc* Feed rate $+5.20000 \mathrm{E}-004 *$ Doc * Coolant flow rate-1.94000E-003* Feed rate*Coolant flow rate $+2.01422 \mathrm{E}-004 * \operatorname{Doc}^{2} *$ Feed rate
Linear Effect: The one factor effects graph shows the linear effect of changing the level of a single factor. It is constructed by predicting the responses for the low (-1) and high (+1) levels of a factor. The one factor method explains the relationship of the factors with the surfaces roughness. The data presented in the 2D diagram (Figure 4) depicts the relationship between flow rate and Ra.

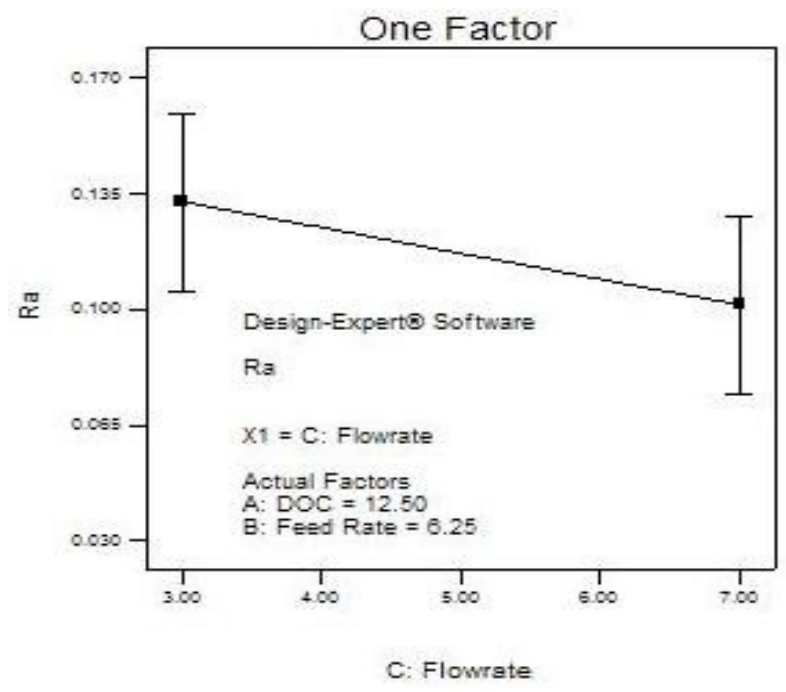

Figure 4: The relationship between Ra versus flow rate, Ra decreasing with increase in flow rate.

It is obvious from the plot that increase in coolant flow rate favours improvement in roughness of ground surfaces examined. It can seen from Figure 5 that feed rate has moderate effect on $\mathrm{Ra}$ value within the parameter range investigated.

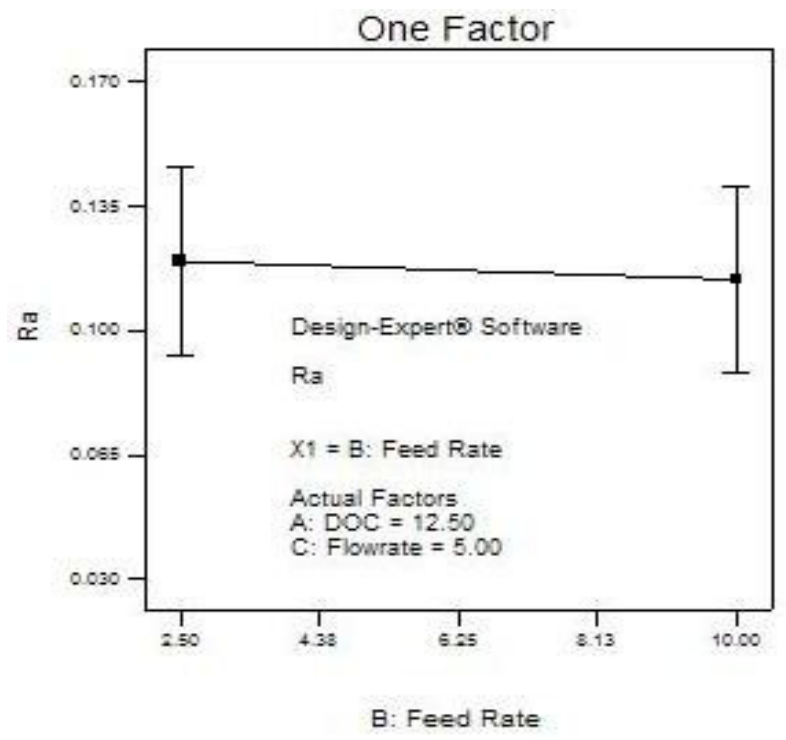

Figure 5: The relationship between $\mathrm{Ra}$ vs Feed rate

For the Figure 6, the surface roughness is proportional with the depth of cut. The values of surface roughness become higher when depth of cut increased. 


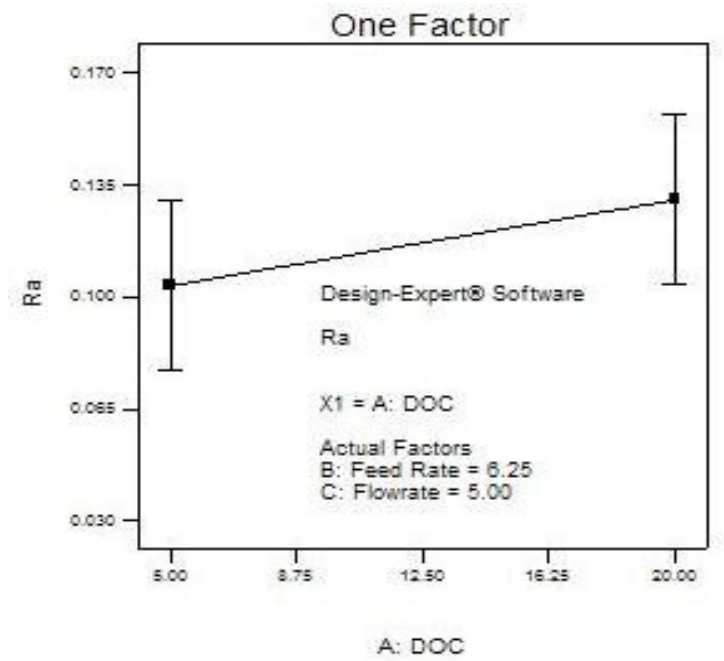

Figure 6: The relationship between Ra vs Depth of cut

\section{Model Diagnostics}

Diagnostic plots of the results is summarised in Figures $7(\mathrm{a}, \mathrm{b}, \mathrm{c})$. Most of the plots display residuals, which show you how well the model satisfies the assumptions of the analysis of variance.

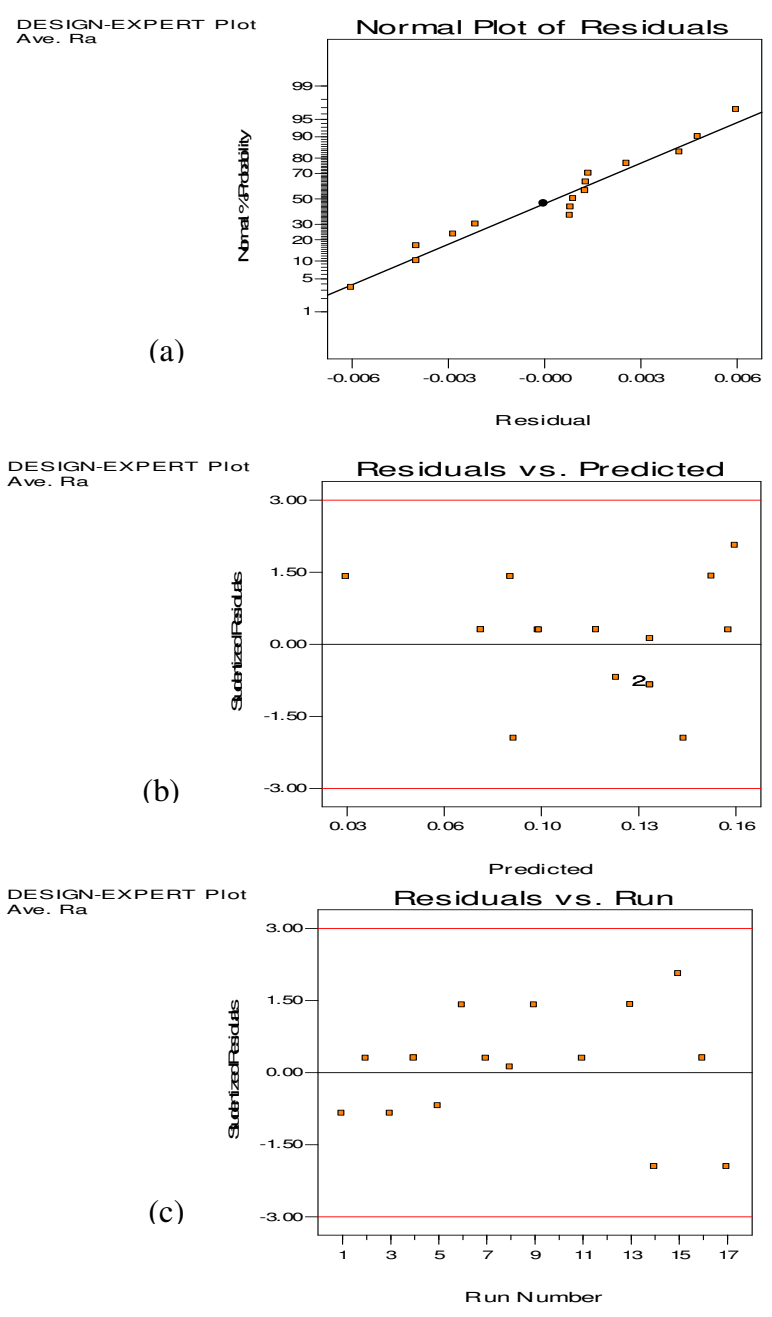

Figure 7: Diagnostic plots of the results

\section{D plots}

Two-factor interaction in the model equation is shown in Figure $8(\mathrm{a}, \mathrm{b}, \mathrm{c})$. The predicted and the actual Ra values based on the model equation are shown in Figure 9.

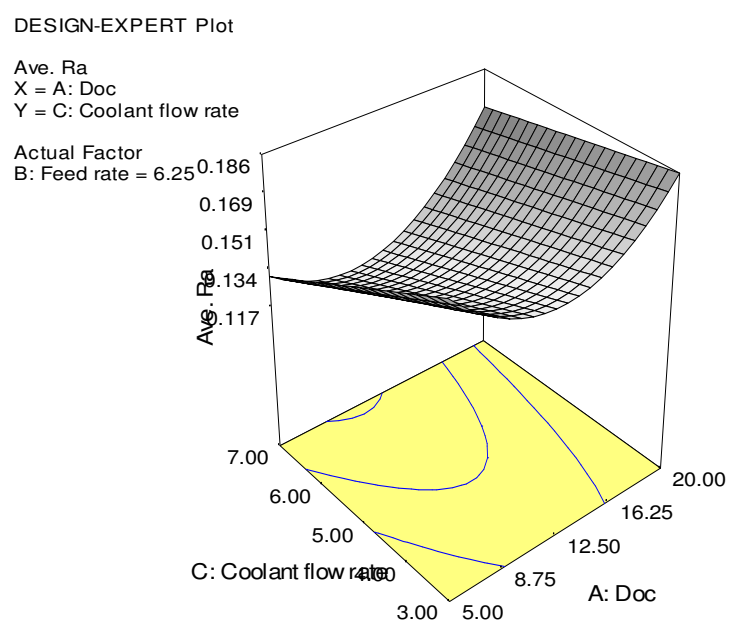

DESIGN-EXPERT Plot

Ave. Ra

$\mathrm{X}=\mathrm{B}:$ Feed rate

$\mathrm{Y}=\mathrm{C}$ : Coolant flow rate

Actual Factor

$A:$ Doc $=12.50$

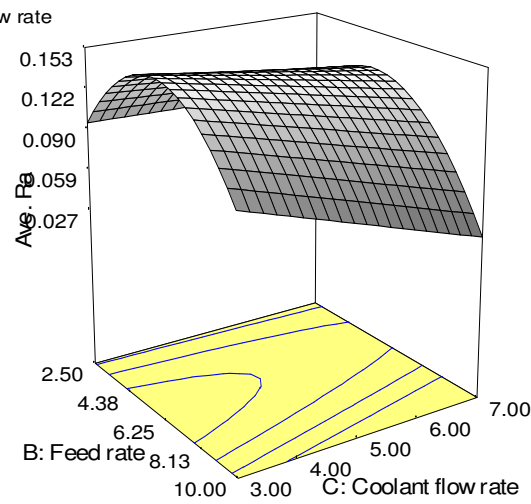

DESIGN-EXPERT Plot

Ave. Ra

$\mathrm{X}=\mathrm{A}:$ Doc

$\mathrm{Y}=\mathrm{B}:$ Feed rate

Actual Factor

C: Coolant flow rate $=4.51$

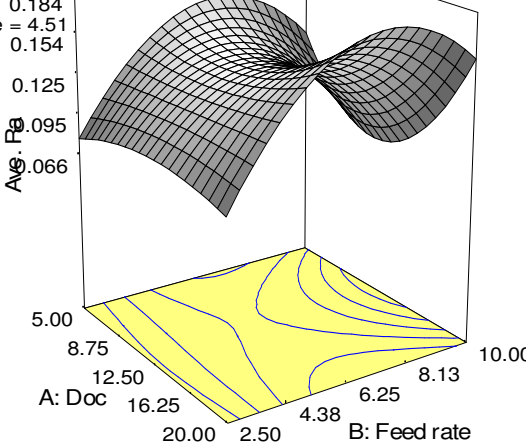

Figure 8: Two-factor interaction model equation 


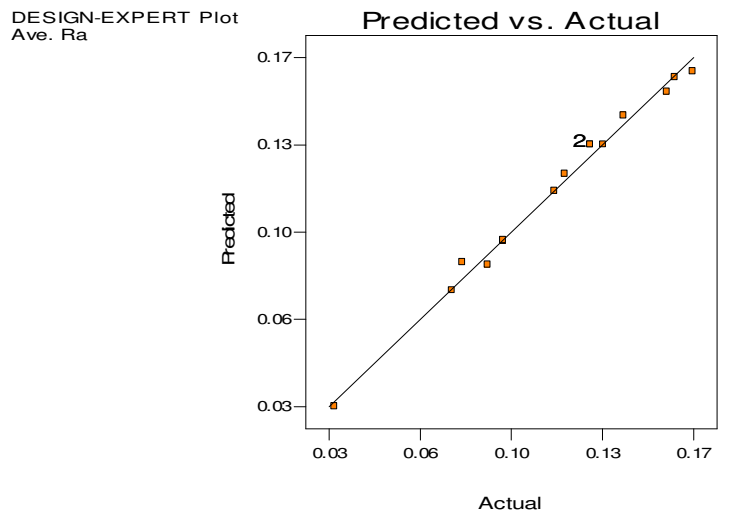

Figure 9: Predicted vs Actual model

\section{Microscopy examinations \\ 6.1 Optical Microscope}

Optical microscopy examination of selected number of trial runs are depicted in the following figures 10 $(a, b \ldots f)$.

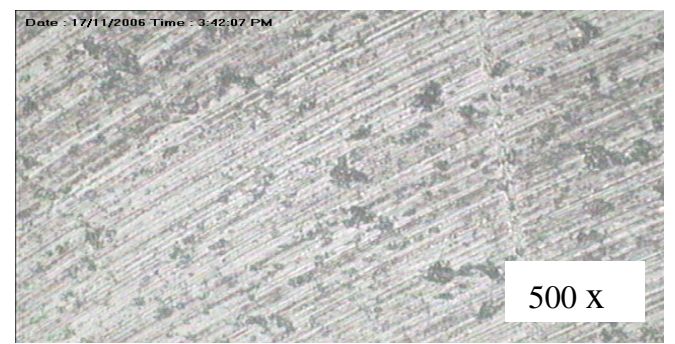

Figure 10(a): Optical image of grounded Si for Run 1 Depth of Cut $=10 \mu \mathrm{m}$, Feed Rate $=5 \mathrm{~mm} / \mathrm{min}$, Flow rate $=5 \mathrm{~L} / \mathrm{min}$

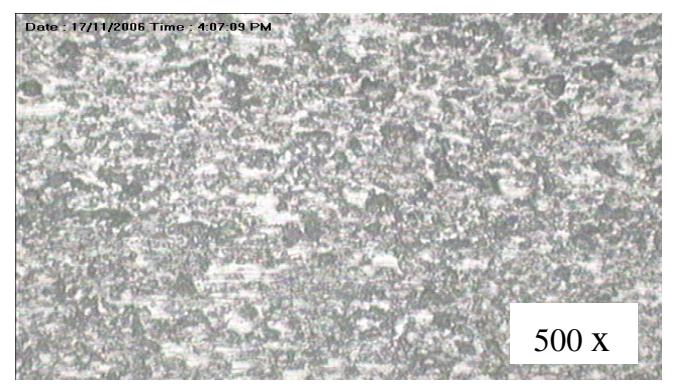

Figure 10 (b): Run 5 Depth of Cut $=5 \mu \mathrm{m}$, Feed Rate $=$ $2.5 \mathrm{~mm} / \mathrm{min}$, Flow rate $=5 \mathrm{~L} / \mathrm{min}$

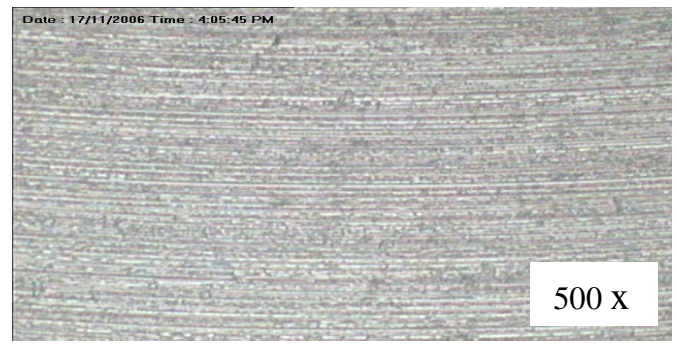

Figure 10(c) Run 6 Depth of Cut $=510 \mu \mathrm{m}$, Feed Rate $=$ $10 \mathrm{~mm} / \mathrm{min}$, Flow rate $=7 \mathrm{~L} / \mathrm{min}$

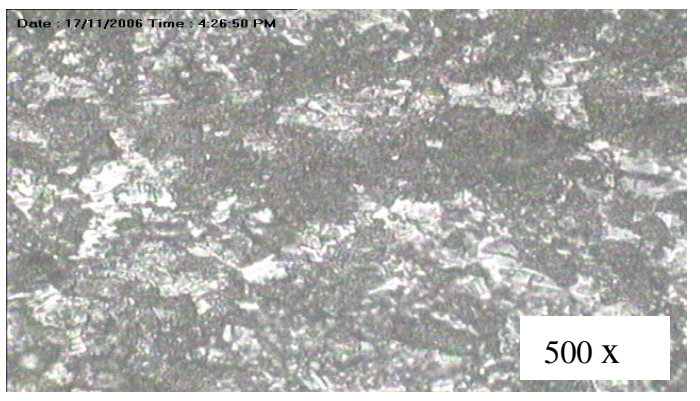

Figure 10 (d): Run 11 Depth of Cut $=20 \mu \mathrm{m}$, Feed Rate $=$ $5 \mathrm{~mm} / \mathrm{min}$, Flow rate $=3 \mathrm{~L} / \mathrm{min}$

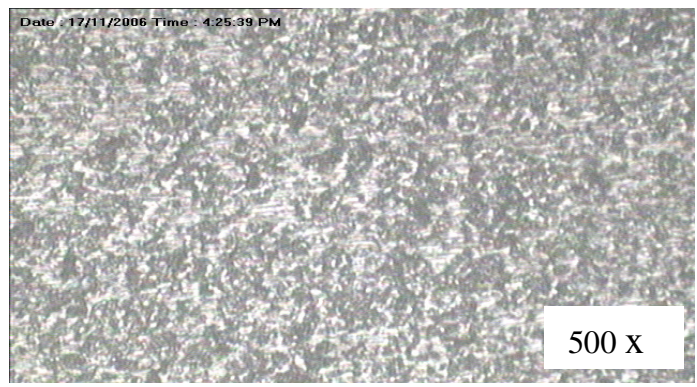

Figure 10(e): Run 15 Depth of Cut $=10 \mu \mathrm{m}$, Feed Rate $=$ $2.5 \mathrm{~mm} / \mathrm{min}$, Flow rate $=7 \mathrm{~L} / \mathrm{min}$

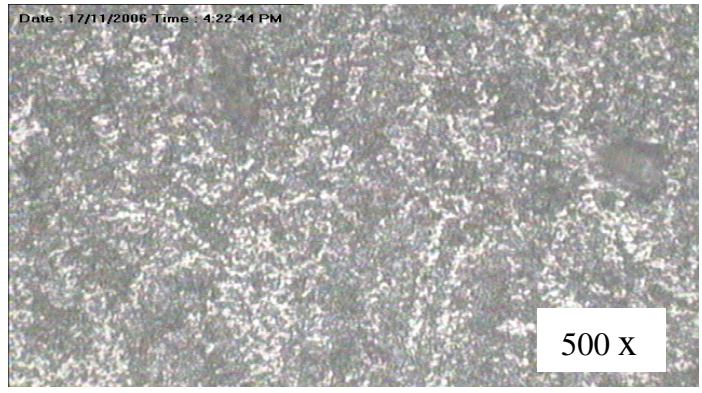

Figure 10 (f) Optical image of grounded Si for Run 14 Depth of Cut $=5 \mu \mathrm{m}$, Feed Rate $=5 \mathrm{~mm} / \mathrm{min}$, Flowrate $=$ $3 \mathrm{~L} / \mathrm{min}$

However, some ground surface exhibit large amount of micro fractures. One of these is illustrated in Figure 11 for Run 11.

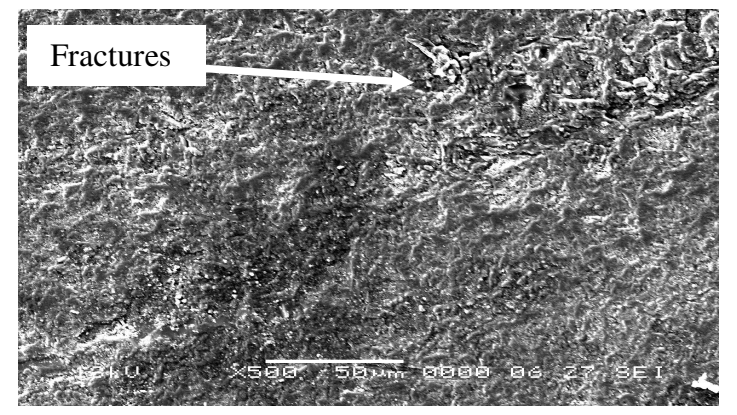

Figure 11: SEM of precision ground Si for Run 11 at Depth of Cut $=20 \mu \mathrm{m}$, Feed Rate $=5 \mathrm{~mm} / \mathrm{min}$, Flowrate $=3 \mathrm{~L} / \mathrm{min}$ showing micro-fractures. 


\subsection{Scanning Electron Microscope}

Detailed study of the surface topography of ground silicon surface was done using SEM. An optical micrographs where ductile streaks were evident were selected. The following SEM Figures 12 and 13 show micrographs with substantial streaks.

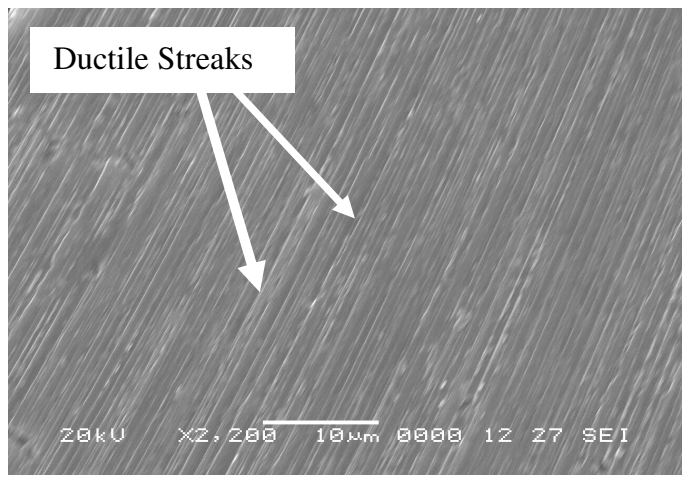

Figure 12: SEM of precision ground Si for Run 1 at Depth of Cut $=10 \mu \mathrm{m}$, Feed Rate $=5 \mathrm{~mm} / \mathrm{min}$, Flow rate $=5 \mathrm{~L} / \mathrm{min}$

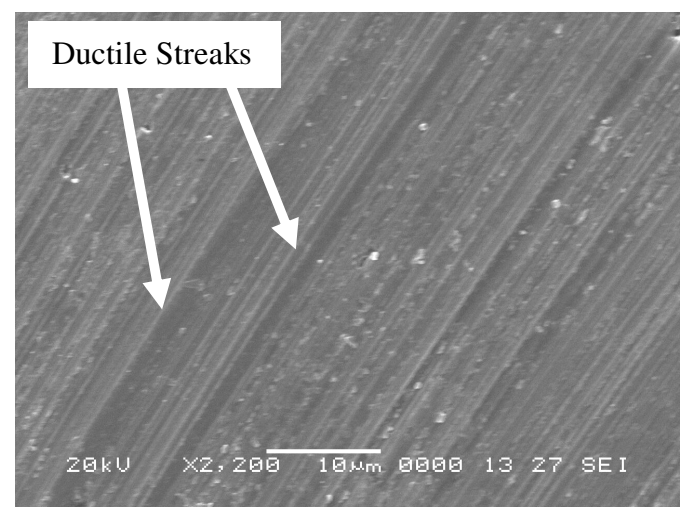

Figure 13: SEM of precision ground Si for Run 6 at Depth of Cut $=10 \mu \mathrm{m}$, Feed Rate $=10 \mathrm{~mm} / \mathrm{min}$, Flow rate $=7$ $\mathrm{L} / \mathrm{min}$ showing massive ductile streaks

All the factors, effect and the interaction the influences of each controllable factor have been determined and their interaction effects on the surface roughness (quality characteristic) were used to determine the opimum conditions. The performances at the optimum conditions were also estimated. Although the highest coolant flow rate gives the better surface roughness, other parameters such as feed rate and depth of cut also influence the surface roughness. There were some results which depend on the feed rate and depth of cut.

For the microstructure analysis, the ductile streaks and fractures occurs on the surface of the sample. The ductile streaks largely appear on the sample with higher coolant flow rate meanwhile the fractures appears more on the sample with lower coolant flow rate.

\section{Conclusion}

On the basis of results obtained, it can be concluded that the optimum condition for best surface roughness and the ductile streak has been achieved at spindle speed $=70$ 000rpm, coolant flow rate $=7$ litters $/ \mathrm{min}$, depth of Cut $=$ $10 \mu \mathrm{m}$, feed Rate $=10 \mathrm{~mm} / \mathrm{min}$. At this condition, a mirror-like finish was observed. The mirror-like surface finish generated on silicon with roughness as low as 0.03 $\mu \mathrm{m}(30 \mathrm{~nm})$.

All the factors involved have an interaction with each other that influence the surface roughness. Different values of the coolant flow rate givee different surface roughness values. More coolant is needed to wash away the chip formation during grinding process in order to avoid any defect to the surface finishing

\section{Acknowledgments}

The authors extend their gratitude to the Research Centre of International Islamic University Malaysia and the Faculty of Mechanical Engineering, Univeristi Teknologi Malaysia (UTM) for their financial support.

\section{References}

[1] Zhong. Z., 1997, Partial-ductile grinding, lapping and polishing on aspheric and spherical surface of glass, Journal of Material and Manufacturing processes. Vol. 12. Issue 6. pp 1063-1073

[2] Zhong. Z. 2003. Ductile or partial-ductile mode machining of brittle materials. The International Journal of Advance Manufacturing Technologies. Vol. 21. Issue 8. pp 579-585

[3] Venkatesh, V.C. et al 1995. Observation on polishing and ultraprecision machining of semiconductor substrates, CIRP Vol 44, No.2, 611-618

[4] F. Engineer, F., Guo, C and Malkin, S., 1992. Experimental measurement of fluid flow through the grinding zone. Trans. ASME. 114 , pp. 61-66

[5] C. Guo and S. Malkin, 1992. Analysis of fluid flow through the grinding zone. Journal of Engineering for Industry 114, pp. 427-434.

[6] Gviniashvili, V. K.. 2003. Useful coolant flow rate in grinding. International journal of Machine Tools and Manufacturer. Vol. 44. Issue 6. pp 629-636.

[7] S. Ebbrell, S. 2000. The effects of cutting fluid application methods on the grinding process. International journal of Machine Tools and Manufacturer. Vol. 40. Issue 2. pp 209-223.

[8] Konneh, M. 2003. An experimental investigation on partial-ductile mode grinding of silicon, $\mathrm{PhD}$ Thesis, Universiti Teknologi Malaysia. 